\title{
HENRI LEFEBVRE. CONTRARRÉPLICA A GEORGE I. GARCÍA HENRI LEFEBVRE. A REPLY TO GEORGE I. GARCÍA
}

\author{
Roy Alfaro Vargas*
}

\author{
El primero de los males es la profesionalización excesiva. \\ Antes filosofar era cosa de aficionados, de amantes de la sabiduría. \\ Desde hace un par de siglos, la filosofía es una profesión como cualquier otra. \\ Mario Bunge \\ Filósofo
}

\begin{abstract}
RESUMEN
Este ensayo es la contrarréplica a "Una réplica a 'La sociología crítica de Henri Lefebvre', de Roy Alfaro Vargas”, de George I. García. Aquí, pretendo centrarme en el análisis de Las Sombras de la Modernidad (del mismo García), con el fin de establecer algunas inconsistencias gnoseo-lógicas. Asimismo, trato de señalar brevemente algunas líneas de investigación derivadas del mismo enfoque lefebvriano, que permitirán el desarrollo de la dialéctica.
\end{abstract}

PALABRAS CLAVE: HENRI LEFEBVRE * NEGATIVIDAD * FILOSOFÍA * MARXISMO * POSTMODERNIDAD $*$ EPISTEMOLOGÍA* SOCIOLOGÍA

\section{ABSTRACT}

This article is in response to George I. García s paper titled "Una réplica a 'La sociología crítica de Henri Lefebvre, de Roy Alfaro Vargas". It is my expectation to draw attention to Las Sombras de la Modernidad by García himself and analyze different problems (blunders) related to Garcia's interpretation of Henri Lefebvre's critical sociology. I show the link between both the Garcia's thought and the postmodern ideology. I also essay to point out some new fields of research stemmed from the Lefebvrian paradigm that will allow growing the dialectical approach.

KEYWORDS: HENRI LEFEBVRE * NEGATIVITY * PHILOSOPHY* MARXISM * POSTMODERNITY $*$ EPISTEMOLOGY $*$ SOCIOLOGY

Candidato a la Maestría Académica en Literatura de la Latinoamericana, Universidad de Costa Rica. royalfarov@gmail.com 


\section{INTRODUCCIÓN}

Durante un curso de Filosofía de lo cotidiano, impartido por el filósofo Eval Araya, hacia finales del siglo pasado, conocí La vida cotidiana en el mundo moderno, de Henri Lefebvre. A partir de ahí, fui encantado por el pensamiento lefebvriano y por la negatividad. Más o menos en el mismo periodo, George I. García desarrollaba al parecer el mismo gusto ${ }^{1}$.

Este escrito continúa este proceso descrito brevemente arriba, en tanto contrarréplica a "Una réplica a 'La sociología crítica de Henri Lefebvre', de Roy Alfaro Vargas", escrito por García ${ }^{2}$. He preferido centrarme en el objeto de discusión, Las Sombras de la Modernidad (LSM), del mismo García; obviando la argumentación ad hominem.

La tesis que nos guiará es la siguiente: en el análisis del pensamiento lefebvriano, García (2001) enfatiza lo histórico, con lo cual la posición cae dentro de un historicismo, el cual reduce la propuesta de Lefebvre a un activismo político, sometido a la diferencia posmoderna.

Para esto, presentaremos resumidamente la posición expresada por García en LSM, con respecto a Lefebvre. Seguidamente, a la tesis garciana, opondremos una propuesta que enfatice lo lógico. Esto nos permitirá aprehender los elementos teórico-interpretativos que tiñen de un color posmoderno, el análisis sobre Lefebvre, realizado por García.

\section{LEFEBVRE SEGÚN GEORGE I. GARCÍA}

El prólogo en cualquier texto funciona como un programador de lectura. O sea, el prólogo es como una entrada durante una comida, que prepara nuestro cerebro para lo que viene, dándole algunas guías iniciales, para ayudar a digerir el texto.

$1 \quad$ Hay un texto de Jorge Chen Sham (1998) en donde él introduce el pensamiento lefebvriano en el análisis literario, pero su lectura de Lefebvre es simplista, reduccionista, ingenua $y$ totalmente positivista.

2

Aparecido en la Revista de Ciencias Sociales 120 (II). 2008: 59-64.
Helio Gallardo indica, en el prólogo de LSM, que "la categoría de praxis es decisivamente política" y que "No es menor el aporte de García al ofrecernos sistemáticamente al Lefebvre fundamental, el del despliegue de una crítica de la vida cotidiana lo que supone valorar lo social como ámbito de la praxis" (García, 2001: 11).

Por tanto, el prólogo nos programa hacia una lectura de corte político, en donde lo social es el espacio de la praxis.

Seguidamente, García señala que lo político es relacional, $y$ que lo cotidiano "es el lugar por excelencia de lo político" (2001: 20) y si lo cotidiano es evidentemente relacional (los ritmos de Lefebvre o lo concebido, lo percibido $y$ lo vivido de The Production of Space, lo ejemplifican); entonces, tanto lo político, como lo cotidiano se definirían como ámbitos relacionales y por ende, no habría, de acuerdo con García, diferenciación alguna entre ellos. Todo sería pura tautología. Petitio principii.

Dentro de este politicismo viciado de circularidad, García expresa que, refiriéndose a LSM, "Hemos querido plantear en este trabajo la necesidad de pensar los conceptos en su génesis histórica, atendiendo a la vez a su genealogía filosófica y las condiciones sociales que posibilitan su producción" (2001: 23). Aquí resuena la episteme foucaultiana, como fue absorbida dentro de la primera sociocrítica montpelleriana, que analiza el texto en su génesis histórica, tratando de establecer el rol del contexto social en la aparición de determinado texto o teoría. Es una forma de genetismo, de historicismo: "Este texto (LSM) intenta elucidar los orígenes de la teorización lefebvriana respecto a la crítica de la vida cotidiana ${ }^{3}$, dando algunas pinceladas sobre

Paréntesis míos. Aquí parece ser mejor "cotidianidad" en lugar de vida cotidiana. Realmente, Lefebvre parte de la separación entre cotidianidad (quotidienneté) y vida cotidiana (vie quotidienne). El primer término se refiere a lo cotidiano tal y como es producido dentro de las sociedades burguesas, dentro del orden cercano. Mientras que la vida cotidiana sería el producto de un acto revolutivo que superaría la cotidianidad burguesa, sería expresión entonces del orden lejano, lo utópico. Cfr.: (Lefebvre, 1972b: 24 y 237). Extrañamente, García conoce esta distinción conceptual (2001: 73), pero incluso así no la aplica, introduciendo 
el cambiante contexto social en el que fueron surgiendo" (García, 2001: 26).

De este modo, junto a la indefinición de lo cotidiano con respecto a lo político, tenemos un historicismo casi en versión foucaultiana. Esto termina de verse claro en la perspectiva que maneja García de la crítica de izquierda: "De este modo, la crítica de izquierda sería una crítica historizada, y que cumpliría la función de cambio a partir de la constatación de la miseria de la vida cotidiana (sic) y de sus posibilidades libertarias" (2001: 48). ¡Miseria de la filosofía! Aquí no puede uno dejar de escuchar el discurso leninista de una conciencia intelectual plena de conocimiento de la realidad y de la injusticia social, que vierte su sabiduría sobre los legos, para guiarlos hacia la revolución.

El asunto, sin embargo, se complica aún más cuando García afirma que "Las prácticas cotidianas carecen de sentido poiético" (2001: 159). Pero, si "lo político se refiere al ámbito de las relaciones de poder" (García, 2001: 20) y esas prácticas cotidianas dadas dentro del ámbito de un Estado, no ofrecen sentido poiético (creativo, dionisiaco, de apropiación); entonces, lo político se enclaustra en un sistema cerrado ${ }^{4}$, ajeno al agente histórico. Si bien el Estado crea una cotidianidad controladora, apolínea; también es cierto que, siguiendo los principios lefebvrianos, lo dionisiaco se va apropiando de pequeños espacios cotidianos, engendrando el potencial de cambio social dado como expresión y desarrollo de la poiesis. No obstante, lo político deviene, según García, una práctica alienante, mitificante, e ideologizante, dentro de un Estado que niega la fête, lo festivo. El panorama no podría ser más sombrío, pero lo es.

Al inicio de LSM, García nos dice que lo cotidiano (las prácticas cotidianas) es lo político par excellence; luego, que las prácticas cotidianas no son un espacio dionisiaco, poiético, con lo cual la contradicción es patente. Sin embargo, para empeorar las cosas, García no

oscuridad en LSM. Incluiremos en adelante un "sic", en donde sea pertinente hacer la corrección conceptual.

Estoy pensando en la teoría clásica de sistemas. Cfr.: (Bertalanffy, 1991). renuncia al contenido mesiánico-apocalíptico $y$ clarividente de aquel vetusto, obsoleto $y$ controlador Diamat ${ }^{5}$, al indicar que "La revolución es la única alternativa a la catástrofe" (2001: $161)^{6}$. No sé cómo, pero repentinamente el pensamiento marxiano-lefebvriano que se niega a plantear ilusiones utópicas ${ }^{7}$, predica que ya sólo hay un único posible, la catástrofe. Nada más anti-dialéctico y anti-lefebvriano que esto.

Dentro de este marco, la siguiente afirmación de García: "El cambio social, producto de la negatividad, es uno de los criterios rectores del texto (refiriéndose a LSM)" (2008: 61) ${ }^{8}$ aparece como lo que es, una frase vacía, un cliché. Cada vez más, la propuesta de García luce como el viejo modelo de interpretación leninista sobre el marxismo.

Por otra parte, el cambio social no es producto de la negatividad, sino de la acción del sujeto histórico concreto, que supera (hebt... auf) su situación cuando las condiciones materiales son las pertinentes, cuando la contingencia deviene necesidad, cuando los cambios cuantitativos dan paso a una nueva cualidad, cuando las formas absolutizadas ceden ante un nuevo contenido. Esto no es un hegelianismo, ni ningún tipo de idealismo, la historia no es,

El Diamat fue la ideología oficial del Estado ruso, durante el período de la Unión Soviética. Esta ideología tenía una gran adaptabilidad, que consagraba toda posible interpretación del pensamiento marxiano, a una serie de instituciones que expresaban siempre la correcta hermenéutica de tal pensamiento. (Cfr.: Paolucci, 2007: 237-238 y 253).

$6 \quad$ Esto es alienante, ya que, implica "la pérdida de lo posible" (Lefebvre, 1970: 187) al reducir lo posible a una única posibilidad. Esta y todas las traducciones de los textos que aparecen en francés, italiano, portugués, inglés y alemán, en la bibliografía, son mías.

7 Raúl Vidales nos ofrece, por otra parte, la distinción entre "realidades utópicas" e "ilusiones utópicas". Las realidades utópicas refieren a lo que todavía no es, pero puede devenir: es la posibilidad presente en la realidad. Al contrario, la ilusión utópica refiere a lo que no puede ser, es decir, lo no posible (1991: 25).

8 Paréntesis míos. Cursiva en el original. 
al modo de una ley natural positivista, el devenir de una negatividad, de un Geist. El devenir es historia y estructura, acción y coyuntura, nunca la expresión de un concepto-ley.

La confusa comprensión de la dialéctica negativa que tiene García, no entendida como la herramienta que ella es, lo lleva a afirmar que Lefebvre "se negó a hablar de la utopía más que en términos de negación del orden social moderno" (2001: 33). ¿Dónde queda entonces la relación dialéctica, utópica, entre los conceptos de orden cercano y orden lejano? El hecho de que Lefebvre no haya querido plasmar tal o cual descripción detallada de cómo podría ser el orden lejano, no le quita el carácter utópico a tal concepto, en tanto niega el orden cercano, que aún hoy (a la vez) lo niega. Lefebvre lo que ha dejado es el camino abierto a otros posibles.

García, no obstante, parece tener un doble vínculo (double bind $)^{9}$ con el concepto de utopía, ya que, "la realización de la vida cotidiana $^{10}$ está en su disolución (...) tal es el horizonte utópico de la crítica lefebvriana de la vida cotidiana (sic)" (2001: 42). Entonces, chay una utopía lefebvriana o no la hay? Si Lefebvre se hubiera quedado en la simple negación del orden existente, sin profundizar en su desmantelamiento, no hubiera pasado de ser un pseudo-intelectual petit bourgeois. Sin utopía no hay pensamiento crítico, ni izquierda.

Para terminar este primer punto, es preciso señalar que hemos podido ver que el enfoque garciano, con respecto a Lefebvre y la negatividad, falló al enfrascarse en una serie de errores lógicos (circularidad, mal manejo conceptual, etc.) y en una maraña de incomprensiones de la dialéctica negativa (e.g.: el mesianismo-apocalíptico de García, historicismo, genetismo, etc.).

Este doble vínculo con la utopía podría venirle a García del pensamiento posmoderno, en donde no hay campo para la utopía, a menos que sea la de mercado.

10 Mejor "cotidianidad" en vez de "vida cotidiana". En esta cita, el término "vida cotidiana" es sumamente equívoco.

\section{ANTI-GARCÍA}

Para continuar nuestra crítica, esta "debe apropiarse pormenorizadamente de su objeto, analizar sus distintas formas de desarrollo y rastrear su nexo interno. Tan solo después de consumada esa labor, puede exponerse adecuadamente el movimiento real (del pensamiento garciano)" (Marx, 1980a: 19) ${ }^{11}$. Debemos entonces, siguiendo de algún modo la lógica de la exposición de Alfred Schmidt en Historia y estructura, introducir un elemento antitético a la posición de García, es decir, lo lógico, el método, lo estructural.

Therborn ubica a Lefebvre dentro de un marxismo filosófico, en tanto filosofía de las contradicciones, con ambiciones onto-epistemológicas y éticas (2007: 67-68). Realmente, el comentario es solo eso, un comentario, y Therborn (convenientemente) $)^{12}$ no profundiza. Pero, no importa, leamos a Lefebvre asumiendo lo lógico del par dialéctico lógico-histórico, como eje fundamental.

En esta perspectiva, dos textos lefebvrianos son sumamente importantes: El materialismo dialéctico y Lógica formal, lógica dialéctica, en los cuales él se centra en el aparato gnoseológico y lógico.

Al igual que Hegel, Lefebvre parte de una crítica al principio lógico-aristotélico de identidad $(\mathrm{A} \equiv \mathrm{A})$. Principio válido dentro de los límites de la lógica formal, pero que más allá de su utilidad en el manejo conceptual, no encuentra asidero en la materialidad del mundo, que es móvil, cambiante, contradictoria $y$ continental. O sea, un principio formalizante $y$ formal que es simplemente "A $\equiv A$. Tautología. Transparencia y vacío. Reducción acabada del contenido" (Lefebvre, 1976b: 12).

Paréntesis míos.

12

Therborn analiza el marxismo post-comunista, olvida la dialéctica y el marxismo no-europeo (el latinoamericano, por ejemplo) deja a la New Light Left americana y europea como la única expresión de la actual izquierda. El primer mundo crea mecanismos de legitimación totalmente excluyentes. 
La crítica del principio de identidad acentúa el énfasis en el contenido, dentro del ámbito de acción de la categoría de abstracto-concreto, en donde de lo elaborado (lo abstracto, lógico) se pasa a lo conocido (lo concreto, lo histórico), en donde la forma abstracta es negada (aufgehoben) por el contenido, para así elevarse a una nueva forma, en un proceso interminable; cazando los pequeños cambios cuantitativos que encierran en-sí, el devenir, el proyecto, el para-sí: "la dialéctica produce ese contenido... (en tanto es) un método de construcción sintético y sistemático del contenido" (Lefebvre, 1974: 55)13. "(Se) Ha de seguir el surgimiento de las formas. (Se) Ha de estudiar el efecto de retorno de las formas sobre los contenidos, de las estructuras sobre los procesos" (Lefebvre, 1972a: 51) ${ }^{14}$. La materialidad, incluyendo lo dado y su negación, establece sus condiciones y la acción las reta. Este es el sustento de la onto-filogénesis del ser humano.

Lefebvre, no obstante, no es Althusser. Para Althusser, la estructura (la forma, lo lógico) es tan fuerte, que el sujeto queda sujetado $y$ anulado, en el proceso de interpelación ideológica. Lefebvre, en cambio, sostiene las bases de la agencia humana, su actuar, como elemento activo sometido y sometedor/a de la materialidad.

Precisamente, es el énfasis sobre la acción humana (herencia marxiana rescatada del idealismo alemán) lo que permite establecer este puente entre lo lógico y lo histórico, entre la teoría y la práctica, entre lo abstracto y lo concreto, entre la forma y el contenido, entre lo particular y lo general:

Lo negativo tiene un poder terrible. Disuelve lo que se da en una unidad; separa lo que está vinculado; el análisis mata; pero precisamente así puede penetrar en los 'seres', desmembrar y reubicar los objetos, captar su génesis en el devenir. La negatividad específica del lenguaje se articula con la del entendimiento $y$ de la acción, sin confundirse con ella (Lefebvre, 1967: 63).
De este modo, no queda duda de la indisoluble unión dialéctica entre lo lógico y lo histórico ${ }^{15}$. De ahí que el historicismo de García es un claro ejemplo de una mala interpretación del pensamiento dialéctico. A García le pasó lo de Gramsci; ambos olvidaron lo lógico, la estructura. García se quedó en "la periodización propuesta por LSM" (2008: 61) ${ }^{16}$. Así, "Las alusiones al carácter negativo de la dialéctica de Lefebvre son parte fundamental de la interpretación en LSM sobre las teorías lefebvrianas de lo cotidiano" (García, 2008: 61) y son, a la vez, la mejor prueba del historicismo que se intenta ocultar tras tantas frases cliché; que en palabras del mismo García, se reduce a la ingenua confesión de que LSM "intenta historizar la teoría" (2001: 23). Como si en el pensamiento dialéctico estuviesen separadas la historia y la teoría (lo lógico). García pretende, con un sesgo positivista, inculcar dentro de lo lógico, lo histórico; olvidando que son una unidad de contrarios, no dos identidades unidas por feedback, por una suerte de interrelación sistémica. Debe ser que LSM no " 'pretendía' ser un libro marxista, y su método fue en ello consecuente" (García, 2008: 61). La separación entre lo lógico y lo histórico no es real; por ende, no es racional.

\section{LA AGONÍA GARCIANA}

García quiso retomar el método regresivo-progresivo de Lefebvre, pero se perdió en la regresión ${ }^{17}$. Así, sufrió aquello que Lefebvre establecía como un peligro: "la parte 'regresiva' arriesga siempre chocar de frente con la parte 'progresiva', de interrumpirla o de obscurecerla" (Lefebvre citado por Hess, 2004).

Quizás esto también le parezca trillado a García, aunque su libro (LSM) atestigüe poca comprensión, por su falta de aplicación, de ello.

De lo cual parece que García está muy orgulloso, a pesar del sesgo anti-dialéctico y por ende, de su carácter positivista.

Incluso intenta, en su obsesión genetista, hallar una filosofía de lo cotidiano en Marx y Engels. Cfr.: (García, 2002a). 
Este método regresivo-progresivo

... consiste en partir de lo actual, luego remontarse al pasado (...) En seguida, se retoma el proceso en un sentido contrario para aclarar, elucidar, desplegar, desarrollar... Uno intenta ver todos los posibles (las 'virtualidades') contenidos en el presente. Uno ensaya así aclarar el futuro teniendo en cuenta lo posible y lo imposible (Hess, 2004) ${ }^{18}$.

Esta movilidad es parte de la idea lefeburiana de la inferioridad de la lógica formal con respecto a la dialéctica (Kelly, 1994: 199), ya que, la lógica formal es incapaz de referirse a fenómenos culturales, sociales, etc., debido a que la lógica formal está enfocada sobre el lenguaje (Villanueva, s.f.e.).

Lefebvre amalgama una serie de ideas: las formas simples se asumen como la síntesis de múltiples determinaciones dadas a lo largo del tiempo ${ }^{19}$, siguiendo a Hegel. De Marx, la idea del método, del materialismo y de la transformación social; junto con la visión de renovación de Nietzsche. "Todos elementos necesarios de su método regresivo-progresivo" (Limonad, 2003).

En este marco, el historicismo garciano niega la dialéctica, cuando solo ve lo antiguo de lo nuevo, en lugar de lo nuevo en lo anti$g^{20}{ }^{20}$. García olvidó que Lefebvre se inspiró en los pueblos rurales de los Pirineos franceses (marcados por su pasado arquitectónico), para luego actualizarlo en el concepto de lo urbano, para plantear la superación de la cotidianidad a través de la vida cotidiana.

De igual modo, cuando García afirma que LSM se centra en la relación cotidianidadmodernidad (2008: 61), cercenando la sociología

Énfasis mío. No solo un posible, como la visión de García.

Esto implica "la cuestión de articular el aporte de diferentes disciplinas para asir un objeto 'complejo'” (Hess, 2004).

20 "La dialéctica es la tentativa para ver lo nuevo de lo antiguo, en lugar de ver solamente lo antiguo de lo nuevo" (Adorno, 1970: 54). lefebvriana anclada en el método regresivoprogresivo. Primero, el historicismo niega la historicidad, en tanto devenir (pasado-presentefuturo), asumida por Lefebvre. En segundo lugar, García no entiende que el enfoque de Lefebvre es sociológico ${ }^{21}$; pero que él, Lefebvre, entiende la Sociología en un modo muy amplio, integrando alrededor de ella la historia y la filosofía. Con la integración de la filosofía, en tercer lugar, afirma no solo el carácter gnoseológico de la filosofía moderna ${ }^{22}$, sino asimismo la noción de totalidad que no aparece en el reducido marco temporal (presente-pasado) del ya mencionado historicismo garciano. Solo así se puede explicar que García me sume dentro de una concepción burguesa y parcelaria de la ciencia (2008: 60).

\section{EL HADES GARCIANO}

Para terminar de sepultar el enfoque dialéctico, García, siguiendo a Zizek, determina que "Si no se tiene en cuenta la diferencia, solamente puede prevalecer una universalidad abstracta, que violenta a los individuos en ella" (2001: 169), siendo la diferencia "una posibilidad que evita (...) la homogenización de los individuos preconizada por el Estado" (García, 2001: 166).

Para Hegel, la diferencia (Differenz) solo podía ser definida en relación con la identidad (Identität), en donde esta última es el fundamento de la primera: solo es posible establecer qué es

Esto es claro en The Production of Space. Ahí, Lefebvre, en las primeras páginas, señala que el espacio asigna un contenido a las relaciones familiares, de producción, etc. De ese modo, el espacio actúa como una instancia de socialización, que siguiendo nuevamente a Lefebvre, permite un proceso de integración-segregación social (cfr.: Lefebvre, 1991: 32-33). Como en la sociología clásica, esta tiene como objeto la relación individuo-sociedad en términos de los mecanismos de integración-segregación que se suceden en determinadas sociedades.

La Crítica de la razón pura, de Kant, establece lo gnoseológico como objeto filosófico fundamental. En algún sentido todas las filosofías post-kantianas son deudoras de Kant. 
diferente cuando se compara con una identidad. Sin embargo, la identidad es, en el mismo proceso, afirmada por la diferencia (Hibben, 2000: 153). Hay una relación de continuidad-discontinuidad entre identidad $y$ diferencia respectivamente. Exempli gratia: una recta representa la continuidad, lo estable, lo idéntico; pero, esta recta está formada por puntos que expresan la discontinuidad. Por lo tanto, dialécticamente, la relación de todos los puntos (las diferencias) forma la recta (la identidad).

Derrida en su momento retoma el concepto de diferencia, para plantear su différence, que se define como una discontinuidad, ya que, "simplemente no pertenece ni a la historia ni a la estructura" (1967: 47). La différence es el fundamento de lo suplementario, concepto con el cual Derrida pretende crear la ilusión de un quebrantamiento del Sistema. La différence difiere del Sistema, con lo cual, según Derrida, la presencia de este Sistema deviene una ausencia generalizada. Todo esto se logra con un juego de lenguaje, en el cual el sentido (sens) se (de)construye en una relación entre significantes. Así, "las cosas vienen a existencia y la pierden al ser nombradas" (Derrida, 1967: 107).

Nada más alejado de la onto-gnoseología dialéctico-marxiana, en donde el objeto es algo dado-construido/construible; es material. El lenguaje no adquiere "sentido" por el acto mágico de la relación entre significantes, sino por su inserción en la praxis.

La différence derridiana es el fundamento de muchos activismos actuales, que buscan afirmar su pretendida diferencia. De este modo, tenemos dentro del ámbito de influencia derridiana, por ejemplo, el feminismo de Helene Cixous o la epistemología de Luce Irigaray. También, el psicoanálisis lacaniano (tan influyente en Zizek, quien es a la vez usado por García como un argumento de legitimación —cfr.: 2001: 169_) es claro ejemplo de esto. Todos estos grupos (feministas, movimiento gay, ecologistas, etc.), con influencia derridiana, luchan contra "la homogenización de los individuos preconizada por el Estado" (García, 2001: 166).

LSM introduce, de este modo, irreflexivamente un elemento teórico-epistemológico de un paradigma no solo ajeno a la dialéctica, sino un modelo que concibe el Ser y su relación con el Deber-ser de una manera totalmente inversa. Amén de la separación entre Ser y Pensamiento.

El paradigma posmoderno del mesías francés, Jacques Derrida, niega la praxis, al reducir todo a lenguaje. La différence derridiana (asumida ingenuamente en LSM) no busca una verdadera transformación (Abänderung) social, sino solamente una simple transformación, una metamorfosis (Verwandlung). Con Derrida, el statu quo capitalista permanece incólume. "Cuando la identidad y la diferencia son usadas como predicados sin una referencia recíproca, se crea la falsa y equivocada abstracción de la mera diferencia o de la mera identidad" (Hibben, 2000: 153).

García debería reconocer que "No solamente la repetición no excluye las diferencias, sino que ella misma las engendra, las produce" (Lefebvre, 1992: 16) ${ }^{23}$. Lefebvre sí asume la différence en todo su sentido hegeliano ${ }^{24}$.

\section{RESURRECCIÓN}

Es hora de abandonar las penumbras del pensamiento garciano $y$ entender que el tiempo de comentar el pensamiento lefebvriano hay que superarlo. El mismo Lefebvre dejó algunas pistas de por dónde iniciar esto.

Es impostergable desarrollar una dialéctica que incluya una idea esbozada por Lefebvre, pero nunca desarrollada a cabalidad, la de que "El tiempo y el espacio absolutos dejaron lugar al tiempo y espacio de la relatividad" (1967: 123). La idea de los ritmos

(La cursiva en negrilla en el original). Recordemos que para Lefebvre la repetición (absoluta) es el principio de identidad de la lógica formal (1992: 16).

\footnotetext{
"No es debido a que la derecha se sirve hoy de esta noción, la diferencia, por lo que es necesario rechazarla. La diferencia es un concepto que habría que apropiárselo, profundizarlo y hacerlo entrar en la práctica, quiero decir, en la práctica política y social de una democracia renovada" (Lefebvre en: Morales, 2001: 523). Es preciso reintroducir la différence en la continuidad.
} 
intenta llevar a cabo esta propuesta, en tanto cada ritmo es un marco de referencia desde donde se considera lo cotidiano, $y$ desde donde cada cual lo asume. Así, lo cotidiano se vive de acuerdo con la relativa posición y ritmo de cada quien, pero siempre es lo cotidiano del capitalismo, lo que se vive. Articulación de lo objetivo y lo subjetivo. Nada de relativismo epistemológico. Nada de posmodernidad.

Sin embargo, esto no basta. Algunos ya hemos iniciado la construcción de conceptos de modelos mentales ${ }^{25}$, que incluyen esta tensión, dentro del espectro de un nuevo par dialéctico de lo mecánico y lo relativo. Par que nos permitiría aprehender los procesos físicos en lo social $y$ viceversa, con el fin de entender cómo el tiempo absoluto de la física mecánica ha determinado ideológicamente el aparato cognitivo y lo social, así como las categorías de tiempoespacio desde Kant ${ }^{26}$.

Dentro de este ámbito, es preciso cuestionar la idea que fundamenta el planteamiento de The Production of Space, referida a que "El espacio (social) es un producto (social)" (1991: 26). Físicamente es muy restrictivo y creo que tentativamente erróneo.

El camino del análisis del tiempo tiene su correlato en algunos textos recientes con cierto ligamen al marxismo; por ejemplo, Sewell $(2008)^{27}$ en el cual él establece un análisis del tiempo en el capitalismo, desde una perspectiva que amalgama el análisis temporal con los

Cfr.: (Alfaro, 2008). Debo, no obstante, aclarar que la idea de hacer concurrir física y dialéctica no viene, en mi caso, por línea lefebvriana; sino a través de un texto de Bitsakis (1975) en donde él presenta algunas ideas interesantes, al respecto de la dialéctica y su vínculo como la relatividad y la mecánica.

26 Ya hemos desarrollado un concepto de ideología derivado del principio de entropía, el cual aparecerá publicado en el 2010.

Un agradecimiento al Sr. William Sewell Jr. (University of Chicago) y al Sr. Noel Castree (Manchester University) por haber compartido sus artículos conmigo. Asimismo, debo agradecer al Sr. Neil Brenner (New York University) por su muy estimable atención para permitirme acceder a su trabajo sobre Henri Lefebvre. ciclos comerciales de este sistema. También, tenemos a Castree (2009) que incorpora, en su análisis del tiempo-espacio capitalista, conceptos marxistas sobre la circulación-producción de mercancías, para explicarnos la espaciotemporalidad capitalista. No obstante, estas investigaciones continúan dentro de una visión temporal absoluta. Si queremos pensar el movimiento real, necesitamos incorporar lo relativo.

Hay que recordar que el marxismo "se expone entonces como el fin de la metafísica, fin de la especulación, fin de la abstracción vacía, porque es ciencia" (Lefebvre, 1970: 55) ${ }^{28}$. "Ser comunista es, esencialmente, adoptar la actitud científica ante los problemas de la sociedad y del hombre" (Lefebvre, 1976d: 201). El marxismo es "la ciencia de la sociedad y de la historia" (Lefebvre, 1976d: 36) ${ }^{29}$.

\section{CONCLUSIÓN}

De hecho, en el análisis del pensamiento lefebvriano, García (en LSM) enfatiza lo histórico, con lo cual la posición cae dentro de un historicismo, el cual reduce la propuesta de Lefebvre a un activismo político, sometido a la diferencia posmoderna. LSM expresa una visión distorsionada del pensamiento lefebvriano. García comete no solo errores de manejo conceptual, sino que también evidencia una poco profunda comprensión de la dialéctica $y$ de su método regresivo-progresivo (recordemos su historicismo y su subyacente interpretación del marxismo como activismo político).

Es común para muchos comentadores de Lefebvre tergiversarlo, para convertirlo en el preámbulo de la estupidez posmoderna o en un simple teórico de lo urbano. Estrategia de la derecha que responde a una globalización, que por un lado habla de la différence (derridiana) $y$ la supuesta solidaridad derivada de ella y por otro lado, somete o elimina cualquier intento de criticar la depravación y obscenidad del modelo del capitalismo financiero actual.

28 La idea de un tiempo absoluto es metafísica, en tanto no es (enteramente) real. 
Muchas veces, sutilmente, se ve entremezclado el pensamiento crítico con alguna filosofía de moda (e.g.: el deconstruccionismo). Y esto es más evidente cuando los académicos tienen que crear mercancías académicas "novedosas" para impulsar el mercado capitalista. La mercantilización y la globalización van pudriendo el trabajo humano. Es preciso recuperar la integridad humana y sobre todo, el derecho a la pereza.

Finalmente, leyendo LSM, uno "se pregunta si ese prevalecer del punto de vista histórico sobre el sistemático no es un síntoma del agotamiento de la filosofía en general" (Löwith, 1971: 101). La excesiva preocupación genética lo demuestra. Dentro de este marco, Lefebvre tiene que ser leído y retomado como quien "buscó impulsar un explícito análisis marxista” (Elden, s.f.e.). Lefebvre impulsó un análisis de la realidad en la articulación dialéctica de lo histórico y lo lógico.

\section{BIBLIOGRAFÍA CONSULTADA}

Adorno, Theodor W. Sobre la metacrítica de la teoría del conocimiento. Estudios sobre Husserl y las antinomias de la fenomenología. Caracas. Monte Ávila Editores, 1970: 292 p.

Alfaro Vargas, Roy. "Relación literaturasociedad. Una aproximación teórica”. Revista de Ciencias Sociales 108 (II). Universidad de Costa Rica, 2005a: 71-78.

Alfaro Vargas, Roy. "Sociología dialéctica de la literatura: cuestión de método". Revista de Ciencias Sociales 109-110 (III-IV). Universidad de Costa Rica, 2005b: 151156.

Alfaro Vargas, Roy. "La sociología crítica de Henri Lefebvre". Revista de Ciencias Sociales 113-114 (III-IV). Universidad de Costa Rica, 2006: 97-104.

Alfaro Vargas, Roy. "Antropologías literarias: prolegómenos a la praxis textual". Praxis: Revista de la Escuela de Filosofía 59. Universidad Nacional, enero-junio 2007a: 7-17.
Alfaro Vargas, Roy. "Forma y movimiento en los estudios literarios". Revista de Ciencias Sociales 117-118 (III-IV). Universidad de Costa Rica, 2007b.

Alfaro Vargas, Roy. "El rol de los modelos mentales espaciales en la aprehensión literaria”. Revista de Ciencias Sociales 121(III). Universidad de Costa Rica, 2008.

Althusser, Louis. Ideología y aparatos ideológicos del Estado. Sétima reimpresión. México. Ediciones Quinto Sol, 1987: 86 p.

Bertalanffy Ludwig von. Teoría general de los sistemas. Traducción: Juan Almeda. Octava reimpresión (1a edición). México. Fondo de Cultura Económica, 1991: 312 p.

Bitsakis, Eftichios. Física contemporánea y materialismo dialéctico. Traducción: José Fernández Valencia. México. Ediciones de Cultura Popular, 1975: 268 p.

Brenner, Neil. "The Urban Question as a Scale Question: Reflections on Henri Lefebvre, Urban Theory and the Politics of Scale". International Journal of Urban and Regional Research 24 (2). 2000: 361-378.

Brenner, Neil. "State theory in the political conjuncture: Henri Lefebvre's 'Comments on a new state form'". Antipode 33 (5). 2001: 783-808.

Camacho, Daniel. "Presentación". Revista de Ciencias Sociales 108 (II). Universidad de Costa Rica, 2005: 7-9.

Castree, Noel. "The Spatio-temporality of Capitalism". Time \& Society 18 (1). 2009: 27-62.

Chen Sham, Jorge. "Territorio y espacio urbano en el México de los 50: Luis Buñuel y Carlos Fuentes". Káñina vol. XXII (3). 1998: 47-55. 
Cros, Edmond. Théorie et pratique sociocritiques. Montpellier. Centre d'Études et Recherches Sociocritiques, 1990: 376 p.

Derrida, Jacques. L'écriture et la différance. Paris. Éditions du Seuil, 1967: 440 p.

Derrida, Jacques. De la gramatología. Buenos Aires. Siglo Veintiuno Editores, 1971: $397 \mathrm{p}$.

Elden, Stuart. s.f.e. "Henri Lefèbvre and die Produktion des Raumes". An Architektur. (en línea). En: <http://semimarx.free. $\mathrm{fr} / \mathrm{IMG} / \mathrm{pdf} / \mathrm{SE}$ _Lefebvre_vers08.pdf $>$ [recuperado el 7 de febrero de 2009].

Engels, Federico. Anti Dühring. Traducción: Traductores Asociados. Quinta edición. Buenos Aires. Editorial Cartago, 1975: $288 \mathrm{p}$.

Foucault, Michel. Las palabras y las cosas. Traducción: Elsa Cecilia Frost. 6a edición. México. Siglo Veintiuno Editores, 1974: $380 \mathrm{p}$.

García Quesada, George I. Las sombras de la modernidad. La crítica de Henri Lefebure a la cotidianidad moderna. San José, Costa Rica. Editorial Arlequín, 2001: 228 p.

García Quesada, George I. "Marx y Engels: la vida cotidiana como praxis". Revista de Filosofía 40 (100). Universidad de Costa Rica, 2002a: 95-102.

García Quesada, George I. "Utopía e ideología: Kandinsky y la modernización del espacio pictórico". Káñina vol. XXVI (2). Universidad de Costa Rica, 2002b: 135145.

García Quesada, George I. "Praxis, totalización e historia en la Crítica de la razón dialéctica”. Revista de Filosofía 63 (109110). Universidad de Costa Rica, 2005: 143-149.
García Quesada, George I. "Una réplica a 'La sociología crítica de Henri Lefebvre', de Roy Alfaro Vargas' ". Revista de Ciencias Sociales 120 (II). Universidad de Costa Rica, 2008: 59-64.

Gramsci, Antonio. Introducción a la filosofía de la praxis. Traducción: S. Solé-Tuna. 3a edición. Barcelona. Ediciones Península, 1976: $160 \mathrm{p}$.

Hibben, John Grier. Hegel's Logic: An Essay in Interpretation. Ontario-Canadá. Batoche Books Limited, 2000: 162 p.

Hegel, G. W. Lógica. Traducción: Antonio Zozaya. 2a edición. Madrid. Editorial Ricardo Aguilera, 1973: 374 p.

Hegel, G. W. Ciencia de la lógica. Traducción: Augusta y Rodolfo Mondolfo. 4a edición. Buenos Aires. Ediciones Solar y Librería Hachette, 1976: 756 p.

Heller, Agnes. Sociología de la vida cotidiana. Traducción: J. F. Ivars y Enric Pérez. 5a edición. Barcelona. Ediciones Península, 1998: $424 \mathrm{p}$.

Hess, Rémi (1991). La méthode d'Henri Lefebvre. 2004 (En línea). En: <http:// multitudes.samizdat.net/article.php3?id article $=618>$ [recuperado el 1 de mayo de 2009].

Jameson, Fredric. Teoría de la posmodernidad. Traducción: Celia Montolío y Ramón del Castillo. 2a edición. Madrid. Editorial Trotta, 1998: $334 \mathrm{p}$.

Kant, Immanuel. Crítica de la razón pura. Traducción: Pedro Ribas. 1a Edición (1a reimpresión). México. Santillana Ediciones Generales, 2007: 694 p.

Kelly, Michael. "Philosophies of Marxism. Lenin, Lukács, Gramsci, Althusser". Richard Kearney (Ed.). Routledge History 
of Philosophy. Twentieth-Century Continental Philosophy vIII. 1994: 184209.

Kouvelakis, Stathis. "Henri Lefebvre, Thinker of Urban Modernity". Bidet, Jacques and Kouvelakis, Stathis (Eds). Critical Companion to Contemporary Marxism. Leiden/Boston. Brill, 2008: Xvii+813 p.

Labica, Georges. s.f.e. Marxisme et poésie. En: <http://lahaine.org/labica/b2-img/ poesie.pdf $>$ [Recuperado el 7 de febrero de 2009].

Lagopoulos, Alexandros Ph. "The Social Semiotics of Space: Metaphor, Ideology, and Political Economy". Semiotica 1731/4. 2009: 169-213.

Lantz, Pierre (1993). La fin et l'histoire: Nietzsche et Lefebvre. 2003. (En línea): $<$ http://multitudes.samizdat.net/article. php3?id_article $=535>$ [recuperado el 1 de mayo de 2009].

Lefebvre, Henri. Lenguaje y sociedad. Traducción: Floreal Mazía. Buenos Aires. Editorial Proteo, 1967: 278 p.

Lefebvre, Henri. La fin et l'histoire. Paris. Les Éditions de Munuit, 1970: 236 p.

Lefebvre, Henri. Sociología de Marx. Traducción: Juan Ramón Capella. Barcelona. Ediciones Península, 1972a: 184 p.

Lefebvre, Henri. La vida cotidiana en el mundo moderno. Traducción: Alberto Escudero. Madrid. Alianza Editorial, 1972b: 256 p.

Lefebvre, Henri. Los marxistas y la noción de Estado. Buenos Aires. Ediciones CEPE, 1972c: $112 \mathrm{p}$.

Lefebvre, Henri. "La significación de la Comuna”. La crisis actual de la política.
Buenos Aires. Rodolfo Alonso Editor, 1972d: $176 \mathrm{p}$.

Lefebvre, Henri. Más allá del estructuralismo. Traducción: Luís Alberto Ruiz. Buenos Aires. Ediciones Península, 1973a: 208 p.

Lefebvre, Henri. El pensamiento marxista y la ciudad. Traducción: Lya de Cardoza. México. Editorial Extemporáneos, 1973b: 176 p.

Lefebvre, Henri. La violencia y el fin de la historia. Traducción: Alfredo Llanos. Buenos Aires. Ediciones Siglo Veinte, 1973c: $240 \mathrm{p}$.

Lefebvre, Henri. Estructuralismo y politica. Traducción: Luís Alberto Ruiz. Buenos Aires. Editorial La Pléyade, 1973d: 248 p.

Lefebvre, Henri. El marxismo. Traducción: Tomás Moro. Buenos Aires. Ediciones CEPE, 1973e: $128 \mathrm{p}$.

Lefebvre, Henri. Contra los tecnócratas. Traducción: Serafina Warschaver. 2a edición. Buenos Aires. Granica Editor, 1973f: $184 \mathrm{p}$.

Lefebvre, Henri. El materialismo dialéctico. Traducción: Rubén A. N. Laporte. Buenos Aires. Editorial La Pléyade, 1974: 192 p.

Lefebvre, Henri. Hegel, Marx, Nietzsche (o el reino de las sombras). Traducción: Mauro Armiño. 2a edición. México. Siglo Veintiuno Editores, 1976a: 292 p.

Lefebvre, Henri. Lógica formal, lógica dialéctica. Traducción: María Esther Benitez. 4 a edición. México. Siglo Veintiuno Editores, 1976b: 350 p.

Lefebvre, Henri. Espacio y política: el derecho a la ciudad II. Traducción: Janina Mul y Jaime Liarás. Barcelona. Ediciones Península, 1976c: 160 p. 
Lefebvre, Henri. Sintesis del pensamiento de Marx. Traducción: Jordi Solé-Tura. Segunda edición. Barcelona. Editorial Nova Terra, 1976d: 328 p.

Lefebvre, Henri. De lo rural a lo urbano. Traducción: Javier González-Pueyo. 4a edición. Barcelona. Ediciones Península, 1978a: 176 p.

Lefebvre, Henri. El derecho a la ciudad. Traducción: Javier González-Pueyo. 4a edición. Barcelona. Ediciones Península, 1978b: 176 p.

Lefebvre, Henri. "A propos d'un nouveau modèle étatique". Dialectiques 27. 1979: 47-55.

Lefebvre, Henri. "The Everyday and Everydayness". Yale French Studies 73. 1987: 7-11. En: <http://www.arch.ttu.edu/ people/faculty/rex_b/CreateWork/Expo/ Expo_ Readings/OnFairs/LefebvreHenri_ TheEverydayAndEverydayness.pdf > [recuperado el 18 de febrero de 2009].

Lefebvre, Henri. The Production of Space. Translated by N. Donaldson-Smith. Oxford. Basil Blackwell, 1991: 455 p.

Lefebvre, Henri. Éléments de rythmanalyse. Introduction à la connaissance des rythmes. Paris. Éditions Syllepse, 1992: 120 p.

Limonad, Ester e Gonçalves de Lima, Ivaldo. Entre a ordem próxima e a ordem distante: contribuições a partir do pensamento de Henri Lefebvre. 2003. (En línea). En: <http://sala.clacso.org. ar/gsdl/cgi-bin/library?e $=$ d-000-00--0ppgeo--00-0-0--0prompt-10---4------011--1-es-Zz-1---20-about---00031-001-00utfZz-8-00\&a $=\mathrm{d} \& \mathrm{c}=$ ppgeo $\& \mathrm{cl}=\mathrm{CL} 1 \&$ $\mathrm{d}=$ HASH013a5bee9f5ebf7331af6c23.3> [recuperado el 7 de febrero de 2009].

Löwith, Karl. Da Hegel a Nietzsche: la frattura rivoluzionaria nel pensiero del secolo XIX. Torino. Einaudi, 1971: 596 p.
Martin, Jean-Yves. "Une géografie critique de l'espace du quotidien: l'actualité mondialisée de la pensée spatiale d'Henri Lefebvre". Revue de Sciences Humaines 2. 2005. (En ligne). En: <http://www. articulo.ch/index.php?action $=$ motscles \& quoi=Critique $>$ [recuperado el 5 de enero de 2009].

Marx, Karl. Crítica al programa de Gotha. s.f.e. (En línea). En: <http://www. misionconciencia.org.ve/website/ critica\%20gotha.pdf> [Recuperado el 29 de abril de 2009].

Marx, Karl. Manuscritos económico-filosóficos de 1844. Traducción: Wenceslao Roces. México. Grijalbo, 1968a: 160 p.

Marx, Karl. Sociología y filosofía social. Traducción: Jordi Solé-Tura. 2a edición. Barcelona. Ediciones Península, 1968b: $288 \mathrm{p}$.

Marx, Karl. Contribución a la crítica de la economía política. 6a edición. México. Ediciones de Cultura Popular, 1976: $280 \mathrm{p}$.

Marx, Karl. Miseria de la filosofía. Respuesta a la "Filosofía de la Miseria" del señor Proudhon. Moscú. Editorial Progreso, 1979a: 200 p.

Marx, Karl. El Capital (tomo I/ vol. 2). Traducción: Pedro Scaron. Sétima edición. México: Siglo Veintiuno Editores, 1979b.

Marx, Karl. El Capital (tomo II/ vol. 4). Traducción: Diana Castro. Quinta edición. México: Siglo Veintiuno Editores, $1979 \mathrm{c}$.

Marx, Karl. El Capital (tomo I/ vol. 1). Traducción: Pedro Scaron. Novena edición. México. Siglo Veintiuno Editores, 1980a: 382 p. 
Marx, Karl. El Capital (tomo I/ vol. 3). Traducción: Pedro Scaron. Sexta edición. México. Siglo Veintiuno Editores, 1980b.

Marx, Karl. El Capital (tomo II/ vol. 5). Traducción: Pedro Scaron. Quinta edición. México: Siglo Veintiuno Editores, 1980c.

Marx, Karl. El Capital (tomo III/ vol. 6). Traducción: León Mames. Cuarta edición. México: Siglo Veintiuno Editores, 1980d.

Marx, Karl. El Capital (tomo III/ vol. 7). Traducción: León Mames. Cuarta edición. México: Siglo Veintiuno Editores, 1980e.

Marx, Karl. El Capital (tomo III/ vol. 8). Traducción: León Mames. Primera edición. México: Siglo Veintiuno Editores, 1981.

Marx, C. y Engels, F. La ideología alemana. San José, Costa Rica. IMCUSA, s.f.e (a): 152 p.

Marx, C. y Engels, F. (b). The Communist Manifesto (audio-book). Translated by Samuel Moore. Librivox Recording. Read by Jon Ingram. s.f.e. (On line). En: <http:// librivox.org/the-communist-manifestoby-karl-marx-and-friendrich-engels/> [recuperado el 30 de agosto de 2008].

Merrifield, Andy. Henri Lefebvre. A Critical Introduction. New York/London. Routledge, 2006: 238 p.
Morales, Nelson. "Filosofía de lo Cotidiano y el Ritmanálisis". Fermentum 32. Año 11. 2001: 517-524.

Paolucci, Paul. Marx's Scientific Dialectics. A Methodological Treatise for a New Century. Leiden/Boston. Brill, 2007: 329 p.

Schmidt, Alfred. Historia y estructura. Traducción: Gustavo Muñoz. Madrid. Alberto Corazón Editor, 1973: 168 p.

Sewell, William Jr. "The Temporalities of Capitalism". Socio-Economic Review 6. 2008: 517-537.

Therborn, Göran. "After Dialectics. Radical Social Theory in a Post-Communist World". New Left Review 43. 2007: 63-114.

Vidales, Raúl. Utopía y liberación: el amanecer del indio. 2a edición. San José, Costa Rica. DEI, 1991: 208 p.

Villanueva Donoso, Jaime. La lógica como ciencia social y el fenómeno de la modernidad; el caso de Henri Lefebvre. s.f.e. (En línea). En: <www.psikeba.com. ar/articulos/JV_el_caso_henri_lefebvre. htm $>$ [recuperado el 16 de octubre de 2008]. 
